\title{
Maternal nutritional manipulation of placental growth and glucose transporter 1 (GLUT-1) abundance in sheep
}

\author{
J. Dandrea, V. Wilson, G. Gopalakrishnan, L. Heasman*, \\ H. Budge, T. Stephenson and M. E. Symonds ${ }^{\dagger}$ \\ Academic Division of Child Health, School of Human Development, University Hospital, \\ Queen's Medical Centre, Nottingham NG7 2UH, UK
}

Glucose transporter 1 (GLUT-1) is the predominant glucose transporter in the placenta but the extent to which its abundance is nutritionally regulated is unknown. This study investigated the effects of restricted maternal nutrition between day 28 and day 80 of gestation followed by re-feeding to either meet or to exceed the total energy requirements on placental size and GLUT-1 abundance at mid-gestation (that is, day 80) and near to term (that is, days 140-145 of gestation; term = 147 days). Singleton bearing ewes either consumed 8.7-9.9 MJ day ${ }^{-1}$ of metabolizable energy (that is, well fed) or 3.2-3.8 $\mathrm{MJ} \mathrm{day}^{-1}$ of metabolizable energy (that is, nutrient restricted) from day 28 to day 80 of gestation, after which stage they consumed either 6.5-7.5 MJ day ${ }^{-1}$ (that is, adequately fed) or 8.0-10.9 MJ day ${ }^{-1}$ (that is, well fed) of metabolizable energy until near to term. In all ewes, at both sampling dates, the abundance of GLUT-1 was higher in the maternal component than in the fetal component of the placenta. Immunohistochemistry confirmed that GLUT-1 was located in the maternal uterine syncytium. At day $\mathbf{8 0}$ of gestation, placental mass was lower $(P<0.05)$ in the nutrient restricted group, but there was no difference in the abundance of GLUT-1 between the nutrient restricted group and the well fed group. At near term, placental mass was greater $(P<0.05)$ in ewes that were nutrient restricted during early to mid-gestation and then adequately fed up to term compared with ewes that were well fed during early to mid-gestation. This increase was associated with a higher $(P<0.05)$ abundance of total placental GLUT-1 and a larger fetus. There was no effect of previous nutrient restriction on placental mass, fetal weight or GLUT-1 abundance at term, when ewes were well fed in the second half of gestation. In conclusion, maternal nutrient restriction between early to mid-gestation alters placental growth but has no effect on placental GLUT-1 abundance. Increasing maternal feed intake to meet calculated energy requirements in previously nutrient restricted ewes during the second half of gestation, increases placental mass and fetal weight, and the abundance of GLUT-1, an adaptation not observed if maternal food intake is increased above requirements.

\section{Introduction}

Humans that are small or disproportionate at birth and have altered placental growth are at an increased risk of developing coronary heart disease, hypertension or noninsulin-dependent diabetes as adults (Barker, 1998). These associations have been suggested to reflect adverse programming of fetal development, although the primary mechanisms underlying this theory remain to be defined. It has also been suggested that alterations in maternal nutrition at critical stages of gestation can result in offspring that are either long and thin after fetal nutrient restriction in early to mid-gestation (Barker et al., 1990, 1992) or short

*Present address: ADAS High Mowthrope, Duggleby, Malton, North Yorkshire YO17 8BP, UK

${ }^{\dagger}$ Correspondence

Email: Michael.Symonds@nottingham.ac.uk and fat after fetal nutrient restriction in late gestation (Barker et al., 1992). Studies in humans and sheep have shown that consuming up to half the required energy requirements for body maintenance and pregnancy during early gestation or early- to mid-gestation results in a normal sized fetus at term, with a disproportionately larger placenta (Heasman et al., 1998; Lumey, 1998; Roseboom et al., 1999).

In sheep, the effect of maternal nutrient restriction on placental mass appears to be inconsistent (Heasman et al., 1999), which may be due, in part, to differences in ewe body weight (McCrabb et al., 1992) and maternal nutrition during the second half of gestation (McCrabb et al., 1991). Studies in Welsh Mountain ewes of similar body weight, age and parity have shown that, although undernutrition in early to mid-gestation initially restricts placental growth (Clarke et al., 1998), when ewes are adequately fed (that is, to meet the metabolizable energy requirements for late gestation), a larger placenta develops without any negative effect on fetal weight (Heasman et al., 1998). These findings 
are consistent with the effects of maternal undernutrition during the first trimester of gestation on the fetal and placental growth of infants born in 1944-1945 during the Dutch famine (Lumey, 1998, Roseboom et al., 1999). The extent to which a decrease in maternal nutrient intake over the period of rapid placental growth may alter its potential nutrient exchange capacity, particularly for glucose, the primary fetal metabolic substrate (Meschia et al., 1980), is unknown. It has also not been determined whether a further increase in maternal nutrition in excess of the calculated energy requirements in late gestation compensates for compromised placental development after prolonged periods of nutrient restriction.

The predominant glucose transporter (GLUT) isoform in human placentae is GLUT-1 (Barros et al., 1995), which in the haemochorial placenta of rats is expressed by trophoblast cells distributed in the junctional and labrynthine regions (Zhou and Bondy, 1993). Localization of GLUT-1 is such that it has been proposed to mediate glucose transport into the placenta as well as the fetus (Zhou and Bondy, 1993; Devaskar et al., 1994). In sheep, placental mRNA for GLUT-1 increases with gestational age and reaches peak values at day 120 of gestation in singleton pregnancies (Currie et al., 1996) compared with day 140 of gestation in twins (Ehrhardt and Bell, 1997). GLUT-3 may also have a role in regulating placental glucose, particularly in late gestation during which both GLUT-3 mRNA and protein expression attain peak values (Ehrhardt and Bell, 1997), although it is not known whether placental GLUT-3 is nutritionally regulated. The extent to which the abundance of placental GLUT-1 alters in response to nutritional manipulation of the ewe at different stages of gestation has not been examined. This study was designed to examine the effects of maternal nutrient restriction from day 28 to day 80 of gestation followed by feeding to either $100 \%$ of metabolizable energy requirements, suitable to produce a $4.5 \mathrm{~kg}$ lamb at term (Agricultural Research Council, 1980) (that is, adequately fed), or $150 \%$ of metabolizable energy requirements (that is, well fed), on placental mass, fetal weight and GLUT-1 abundance. It was hypothesized that during early- to mid-gestation, when total fetal glucose requirements are low, placental GLUT-1 abundance is not affected by maternal undernutrition, but the subsequent capacity of the placenta to enhance GLUT-1 abundance is re-set by nutrient intake in both early and late gestation.

\section{Materials and Methods}

\section{Animals and nutrition}

Thirty-four Welsh Mountain ewes of similar age (median 3 years) and weight $(36.1 \pm 0.9 \mathrm{~kg}$; mean $\pm \mathrm{SE})$ that were confirmed to be pregnant with a single fetus at days 40-42 of gestation were used in this study. All ewes were mated at a known date with one of two Texel rams that weighed 87 and $89 \mathrm{~kg}$, respectively. Body condition score was assessed by the distribution of fat and muscle in the lumbar region, on and around the backbone in the loin area immediately behind the first rib, as described by Russel et al. (1969), using a scale of $0-5$, with 0 indicating very thin and 5 grossly overweight. At the start of the study ewes weighed $32.7 \pm 0.2 \mathrm{~kg}$. Ewes were housed individually at day 28 of gestation and were fed each day between 08:30 and 09:00 h. The ewes were allocated to one of two nutritional groups using a stratified randomization method by body weight, and were fed a diet of hay and concentrate identical to that used by Heasman et al. (1998). Metabolizable energy requirements for each ewe were calculated according to their body weight, taking into account requirements for both ewe maintenance and growth of the conceptus on the basis of producing a $4.5 \mathrm{~kg}$ lamb at term (Agricultural and Food Research Council, 1992). Diets were adjusted every 2 weeks and were increased at day 43 and day 61 of gestation to meet the higher metabolizable energy requirements associated with growth of the conceptus. Nutrient restricted ewes were given, and consumed, $60 \%$ of their calculated metabolizable energy requirements, that is, 3.2-3.8 MJ day $^{-1}$, with the exception of one ewe that did not eat all the hay provided. Well fed ewes were given 225\% of their calculated metabolizable energy requirements of which they consumed approximately $150 \%$, as not all the hay was eaten, that is, a daily metabolizable energy intake of 8.0-10.9 MJ day ${ }^{-1}$. Ewes that were selected randomly to be sampled near to term were divided into a further two nutritional groups after day 80 of gestation. The amount of feed provided was increased at day 100 and day 120 of gestation to account for the increase in fetal energy demands (Agricultural Research Council, 1980). Ten ewes (five previously nutrient restricted and five previously well fed) were given $100 \%$ of calculated metabolizable energy requirements (that is, adequately fed) and consumed 6.5-7.5 MJ day ${ }^{-1}$. The remaining 14 ewes (that is, seven previously nutrient restricted and seven previously well fed) were given $150 \%$ of the calculated metabolizable energy requirements (that is, well fed) and consumed 8.0-10.9 MJ day $^{-1}$. In summary, at term there were four nutritional groups: (i) nutrient restricted followed by adequately fed $(n=5)$; (ii) well fed followed by adequately fed $(n=5)$; (iii) nutrient restricted followed by well fed ( $n=7$ ); and (iv) well fed followed by well fed $(n=7)$. All operative procedures and experimental protocols had the required Home Office approval as designated by the Animals (Scientific Procedures) Act (1986).

\section{Experimental design}

At day 78 and days 138-140 of gestation, a jugular venous catheter was inserted into each ewe. The next day, blood samples were collected at $1 \mathrm{~h}$ intervals between 08:00 and 16:00 h, and the animals were fed each day at 09:00 h. At day 80 of gestation, five nutrient restricted and five well fed ewes were selected at random and killed by i.v. administration of barbiturate (100 mg pentobarbital sodium 
$\mathrm{kg}^{-1}$, Euthatal). The entire uterus was removed and the fetus was killed with barbiturate, after which all major organs were dissected and weighed. Crown-rump length (from the middle of the occiput to the base of its tail) was measured. For each ewe, type A placentomes were chosen at random, dissected immediately, separated into their maternal and fetal components and placed in liquid nitrogen. These samples were then stored at $-80^{\circ} \mathrm{C}$ until analysed. In addition, whole placentomes were fixed in $10 \%(\mathrm{v} / \mathrm{v})$ formalin and embedded in paraffin wax for histological analysis. All remaining individual placentomes were dissected and typed according to the degree of eversion or growth of the fetal cotyledon over the maternal caruncle, which can be identified clearly as the two tissues differ greatly in their physical appearance (Alexander, 1964). Inverted placentomes were classified as type $\mathrm{A}$ and everted placentomes as type $\mathrm{D}$, with types $\mathrm{B}$ and $\mathrm{C}$ as intermediate (Vatnick et al., 1991). Each placentome was gently separated into its fetal and maternal components, and the respective tissues were weighed. Some residual fetal tissue was present on the maternal side after this procedure. The same procedure was repeated for the remaining ewes between day 140 and day 145 of gestation. There was no difference in the ratio of maternal:fetal tissue separated between the groups, or in the type of cotyledon or gestational age (for example, ratio of maternal:fetal tissue for well fed ewes at day 80 of gestation was 0.76:0.24 and near to term this ratio was 0.78:0.22).

\section{Laboratory procedures}

Crude protein homogenates were prepared from all placental samples using radioimmunoprecipitation buffer containing $1 \%(\mathrm{v} / \mathrm{v})$ nonidet P-40, $0.5 \%(\mathrm{w} / \mathrm{v})$ sodium deoxycholate, $0.1 \%(\mathrm{w} / \mathrm{v})$ sodium dodecyl sulphate, 100 mmol sodium orthovanadate $\mathrm{I}^{-1}, 0.01 \%(\mathrm{w} / \mathrm{v})$ phenylmethyhylsulphonyl fluoride and $0.03 \%(\mathrm{v} / \mathrm{v})$ aprotinin in PBS. Three millilitres of radioimmunoprecipitation buffer was used per gram of tissue. The protein content (Lowry et al., 1951) of each preparation was determined and $50 \mu \mathrm{g}$ of each sample used for GLUT-1 detection. The abundance of GLUT-1 was determined after separation by SDS-PAGE followed by immunoblotting and enhanced chemiluminesence (Amersham International) (Bispham et al., 1999), using antibodies raised against rodent GLUT-1 (Alpha Diagnostic, San Antonio, TX), which detects a single protein at $37 \mathrm{kDa}$ that is GLUT-1 in the ovine placenta (Ehrhardt and Bell, 1997) (Fig. 1). Specificity of detection was confirmed using non-immune rabbit serum. Densitometric analysis was performed on each membrane after image detection using a Fujifilm LAS-1000 cooled CCD camera (Fuji Photo Film Co. Ltd, Tokyo). All gels were run in duplicate and the results were expressed as a percentage of a reference sample that was included on all gels (that is, day 80 of maternal placentome). Total placental protein was then used to calculate the abundance of total placental GLUT- 1 for each ewe.

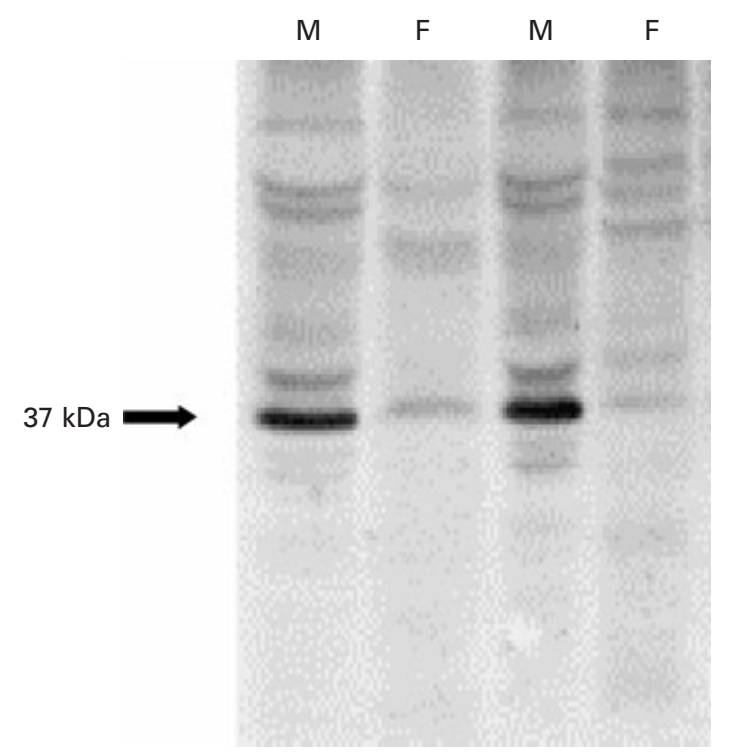

Fig. 1. Immunoblot showing the abundance of glucose transporter 1 (GLUT-1) in the maternal (M) and fetal (F) components of the placenta sampled from ewes near term.

Placentomes embedded in paraffin wax were cut in the same orientation (Sledge microtome, Anglia Scientific, Norwich) and into representative serial sections of $4 \mu \mathrm{m}$ on to aminopropyltriethoxysilane (APES)-treated slides (2\% APES in dry acetone, dried at $42^{\circ} \mathrm{C}$ for $16 \mathrm{~h}$ ). Multiple sections per placentome, two placentomes per ewe and five ewes per group were examined. After the sections were fixed at $37^{\circ} \mathrm{C}$ for $16 \mathrm{~h}$, they were immersed in xylene, twice, for $5 \mathrm{~min}$ to remove the wax. Endogenous peroxidase activity was quenched by 10 min incubation in $6 \%(\mathrm{v} / \mathrm{v})$ hydrogen peroxide solution and sections were then rehydrated in a series of ethanol. Epitopes were exposed by denaturing (incubated in 0.1 mol citrate buffer $\mathrm{I}^{-1}(\mathrm{pH}$ 6; $2.9 \%(\mathrm{w} / \mathrm{v})$ trisodium citrate with $15 \mathrm{~min}$ microwave irradiation). Sections were incubated with antibodies raised against rodent GLUT-1, as described above for immunoblotting, at $4^{\circ} \mathrm{C}$ for $16 \mathrm{~h}$. The antibody was diluted 1 in 400 with $0.25 \%(\mathrm{w} / \mathrm{v}) \mathrm{BSA}$ in 0.005 mol Tris-buffered saline $\mathrm{I}^{-1}(0.88 \%(\mathrm{w} / \mathrm{v})$ sodium chloride, $0.06 \%$ Tris $)$. In between incubations, excess unbound antibody was removed by washing with Tris-buffered saline. Sections were incubated with anti-rabbit immunoglobulin second antibody conjugated to horseradish peroxidase (HRP, DAKO EnVision, CA) at room temperature for $30 \mathrm{~min}$, washed with Tris-buffered saline and incubated with diaminobenzidine (DAB) chromogen substrate (DAKO) at room temperature for $30 \mathrm{~min}$. Evidence for non-specific binding of reagents was obtained by performing the procedure in an identical manner, with the exception of the exclusion of primary GLUT-1 antibody. Sections were examined by light microscopy and immunohistochemical localizations were performed a minimum of three times to 

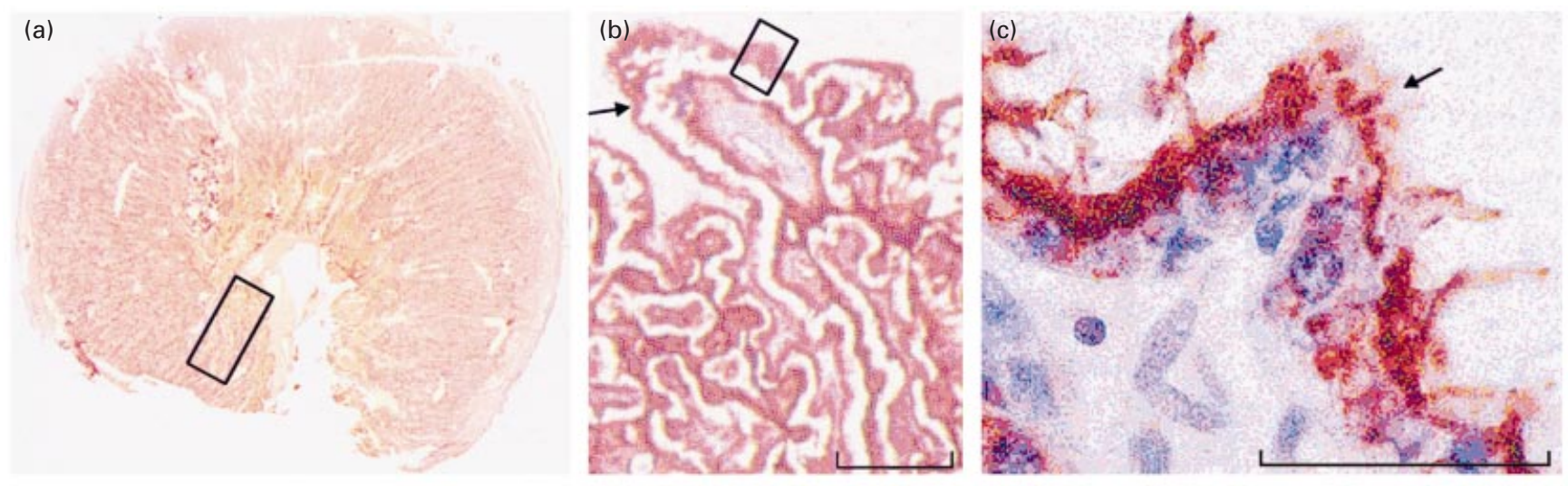

Fig. 2. Localization of glucose transporter 1 (GLUT-1) (increasing magnification as indicated by each box) within the maternal uterine syncytium of ewe placenta at mid-gestation. Macroscopic appearance of a placentome (a) and immunohistochemical localization of GLUT-1 (a,b). Staining for GLUT-1 is seen in the maternal epithelium as indicated by the arrows. Scale bars represent $10 \mu \mathrm{m}$.

ensure representative illustrations. Maternal plasma concentrations of glucose were determined enzymatically as described by Symonds et al. (1986).

\section{Statistical analysis}

The effect of maternal nutrition at each gestational age sampled was assessed using a general linear model procedure for ANOVA (StatView; Abacus Concepts Inc. Berkeley, CA ). In the case of plasma glucose, a mean value was used for each ewe calculated from the values taken at $1 \mathrm{~h}$ intervals between 08:00 and 16:00 h. The results presented are means \pm SEM.

\section{Results}

\section{Ewe body weight and metabolic status}

Nutrient restricted ewes weighed less than well fed ewes at day 80 of gestation (nutrient restricted ewes: $36.3 \pm$ $0.8 \mathrm{~kg}(n=17)$, well fed ewes: $38.2 \pm 0.7 \mathrm{~kg}(n=17)$; $P<0.05$ ) and had a lower body condition score (nutrient restricted ewes: $1.8 \pm 0.1$ arbitrary units (a.u.), well fed ewes: $2.4 \pm 0.2$ a.u.; $P<0.01$ ). At near term, there was no difference in ewe body weight or body condition score irrespective of dietary regimen (for example, body weight: nutrient restricted followed by well fed ewes: $42.9 \pm 1.2 \mathrm{~kg}$ $(n=7)$, well fed followed by well fed ewes: $43.9 \pm 1.0 \mathrm{~kg}$ $(n=7)$; body condition score: nutrient restricted followed by well fed ewes: $1.6 \pm 0.2$ a.u., well fed followed by well fed ewes: $1.8 \pm 0.1$ a.u.), as there was an increase in body weight in all ewes. Mean plasma glucose concentration was lower in nutrient restricted ewes at day 79 of gestation (nutrient restricted ewes: $3.16 \pm 0.05 \mathrm{mmol} \mathrm{I}^{-1}(n=11)$, well fed ewes: $\left.3.71 \pm 015 \mathrm{mmol} \mathrm{I}^{-1}(n=11) ; P<0.01\right)$ but not in ewes near to term, irrespective of the dietary group (for example, nutrient restricted followed by well fed ewes: $3.26 \pm 0.11 \mathrm{mmol} \mathrm{l}^{-1}$, well fed followed by well fed ewes: $\left.3.45 \pm 0.12 \mathrm{mmol} \mathrm{l}^{-1}\right)$.

\section{Localization, abundance and total placental content of GLUT-1 and fetal size}

For each ewe at each age sampled, the abundance of GLUT-1 was higher in the maternal component compared with the fetal component of placenta (Fig. 1). Immunohistochemistry confirmed that GLUT-1 was localized in the maternal uterine syncytium (Fig. 2). At day 80 of gestation, placental mass was lower in the nutrient restricted group (Fig. 3a), but there was no difference in total placental GLUT-1 between the nutrient restricted group and the well fed group (Fig. 4a). Although, fetal body weight (nutrient restricted ewes: $235 \pm 10 \mathrm{~g}(n=5)$, well fed ewes: $214 \pm 7$ $\mathrm{g}(n=5))$ and organ masses (data not shown) were similar between the nutrient restricted group and the well fed group at this age, crown-rump length was greater in the nutrient restricted group (nutrient restricted ewes: $19.8 \pm 0.4 \mathrm{~cm}$, well fed ewes: $18.3 \pm 0.2 \mathrm{~cm}(P<0.05)$ ).

At near to term, the abundance of total GLUT-1 in the placenta was affected by previous nutrient restriction in accordance with changes in placental mass. In ewes that were adequately fed in late gestation, there was an increase in total placental mass $(P<0.05)$ in ewes that were nutrient restricted between day 28 and day 80 of gestation compared with those ewes that were well fed during the same period (Fig. 3b). The increase in placental mass was associated with an increase in total placental GLUT-1 content (Fig. 4b), and with a fetus that was larger (nutrient restricted followed by adequately fed ewes: $3.82 \pm 0.25 \mathrm{~kg}$ $(n=5)$; well fed followed by adequately fed ewes: $2.99 \pm$ $0.09 \mathrm{~kg}(n=5 ; P<0.05)$ and longer (nutrient restricted followed by adequately fed ewes: $52.6 \pm 1.1 \mathrm{~cm}$; well fed followed by adequately fed ewes: $46.4 \pm 0.05 \mathrm{~cm}$; $P<0.001)$, but organ mass per kg body weight was similar between the groups (data not shown). In contrast, when ewes were well fed in the second half of gestation, there was no difference in placental mass or total GLUT-1 abundance between nutritional groups (Figs $3 \mathrm{~b}$ and $4 \mathrm{~b}$ ). Fetal weight 

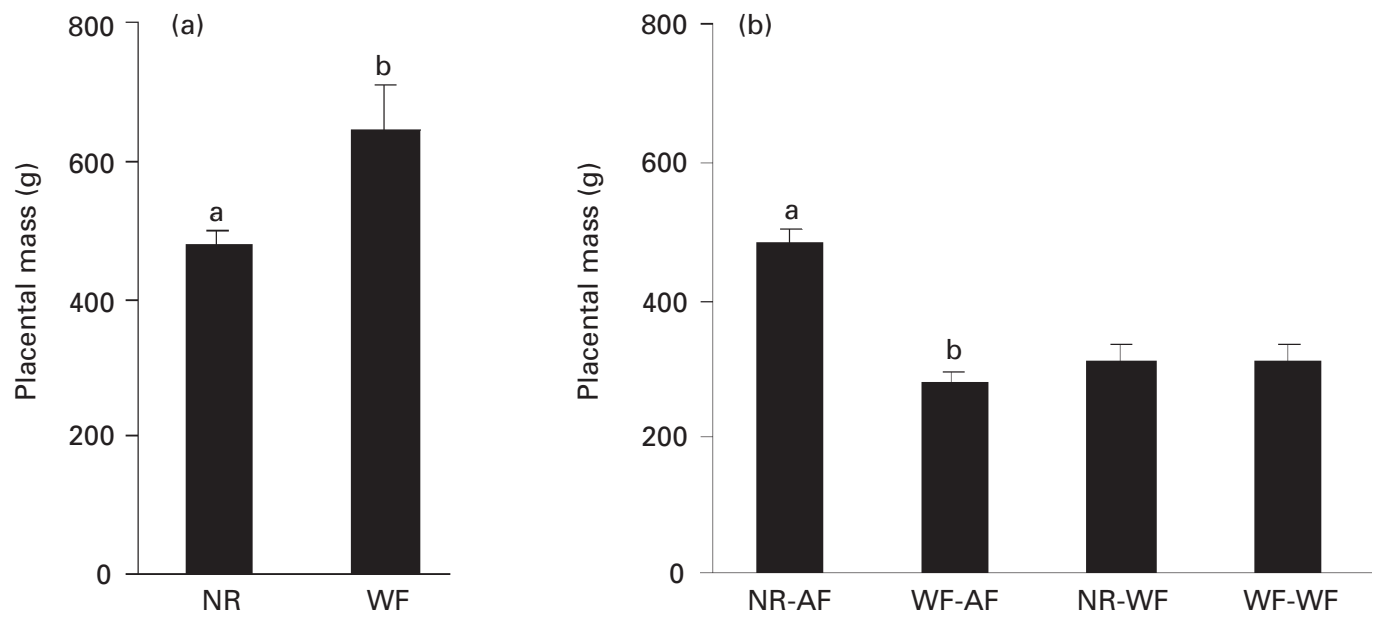

Fig. 3. Effect of maternal nutrition on placental mass at (a) mid-gestation (day 80) and (b) near to term (days 140-145). (a) Ewes were either nutrient restricted (NR) or well fed (WF) between day 28 and day 80 of gestation. (b) Ewes were NR between day 28 and day 80 of gestation, and then either adequately fed (AF; NR-AF) or WF up to term (NR-WF); or ewes were well fed (WF) between day 28 and day 80 of gestation and then AF (WF-AF) or WF up to term (WF-WF). Values are means \pm SEM and $n=5-7$ per group. WF and NR groups at day 80 of gestation, and WF and NR groups at day 80 of gestation that were either AF or WF in late gestation with different letters are significantly different; $P<0.05$.
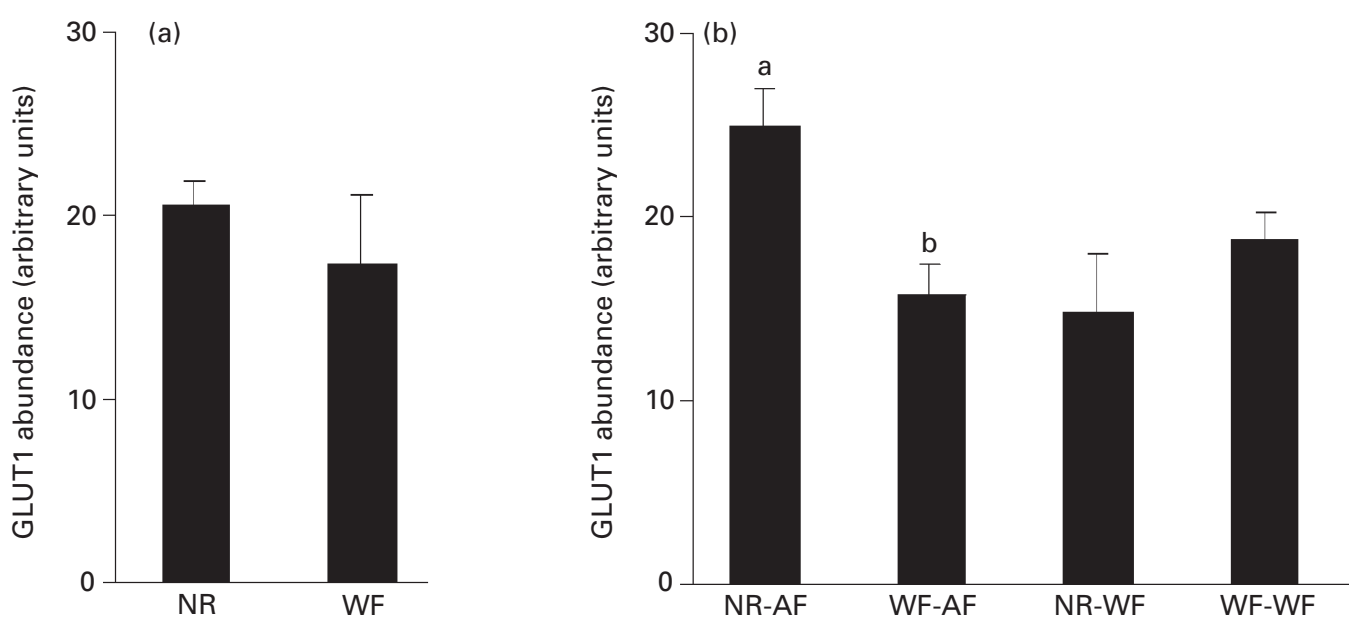

Fig. 4. Effect of maternal nutrition on the abundance of total placental glucose transporter 1 (GLUT-1) at (a) mid-gestation (day 80) and (b) near to term (days 140-145). (a) Ewes were nutrient restricted (NR) or well fed (WF) between day 28 and day 80 of gestation. (b) Ewes were NR between day 28 and day 80 of gestation, and then either adequately fed (AF; NR-AF) or WF up to term (NR-WF); or ewes were well fed (WF) between day 28 and day 80 of gestation and then AF (WF-AF) or WF up to term (WF-WF). Values are means \pm SEM and $n=5-7$ per group. WF and NR groups at day 80 of gestation, and WF groups at day 80 of gestation that were either AF or WF in late gestation with different letters are significantly different; $P<0.05$.

(nutrient restricted followed by well fed ewes: $4.80 \pm$ $0.31 \mathrm{~kg}$; well fed followed by well fed ewes: $4.78 \pm$ $0.22 \mathrm{~kg}$ ), organ masses and length (data not shown) were also similar between groups, but fetuses were larger compared with those sampled from adequately fed ewes.

\section{Placental morphology}

In all ewes sampled at day 80 of gestation, most placentomes showed type A morphology (nutrient restricted ewes: $100 \pm 0 \%(n=5)$, well fed ewes: $94 \pm 6 \%(n=5))$. 
Near to term, irrespective of nutrient intake, ewes that were nutrient restricted during early to mid-gestation had significantly fewer inverted placentomes (for example, type A: nutrient restricted followed by well fed ewes: $41 \pm 17 \%$ $(n=7)$, well fed followed by well fed ewes: $63 \pm 5 \%$ $(n=7))$ and more everted placentomes (type B: nutrient restricted followed by well fed ewes: $26 \pm 8 \%$, well fed followed by well fed ewes: $19 \pm 4 \%$; type C: nutrient restricted followed by well fed ewes: $16 \pm 7 \%$, well fed followed by well fed ewes: $5 \pm 3 \%$; and type D: nutrient restricted followed by well fed ewes: $18 \pm 9 \%$, well fed followed by well fed ewes: $2 \pm 1 \% ; P<0.01)$. The weight distribution of individual placentomes also differed between nutritional groups; ewes that were nutrient restricted had smaller placentomes at both day 80 of gestation (Fig. 5a) and near to term (Fig. 5b). There was no effect of nutrient restriction or gestational age on the number of placentomes (for example, near to term, nutrient restricted followed by well fed ewes: $76 \pm 3$, well fed followed by well fed ewes: $84 \pm 3$ ).

\section{Discussion}

Manipulating maternal nutrition at different stages of gestation can have differential effects on placental mass or fetal weight, which can be dissociated from changes in the abundance of GLUT-1 within the placenta. At day 80 of gestation, after 52 days of maternal nutrient restriction during the period of rapid placental growth (Ehrhardt and Bell, 1995), although there is a decrease in placental mass, there is no change in total placental GLUT-1 content. Fetal weight is maintained and there is a $10 \%$ increase in the length of the fetus. These adaptations occurred despite a $0.5 \mathrm{mmol} \mathrm{I}^{-1}$ decrease in maternal plasma glucose at the end of the period of maternal undernutrition. As all ewes remained normoglycaemic, GLUT-1 does not appear to be sensitive to chronic changes in plasma glucose within the normal physiological range.

The present study demonstrates that GLUT-1 is located predominantly within the maternal uterine syncytium of the placenta in ewes. Localization within the feto-maternal border of the placenta indicates that GLUT-1 may be important in regulating glucose transport to the fetus (Devaskar et al., 1994). In the present study, quantitative measurements of GLUT-1 indicate that placental mass is the main factor determining the abundance of total GLUT-1 near to term, a time when placental GLUT-1 is known to reach peak values (Ehrhardt and Bell, 1997).

Between mid- and late gestation, when nutrient intake was increased in ewes that had been nutrient restricted in early gestation, placental mass and total GLUT-1 abundance were maintained. This period of increased nutrient intake coincides with the period of placental development when there is an increase in vasculature (Stegmann, 1974). At near term, ewes that had been nutrient restricted during early gestation and then adequately fed during mid- to late gestation produced a fetus that was longer and weighed more compared with ewes that were well fed during early gestation. It is not known whether placental adaptations act directly to promote fetal growth. The abundance of placental GLUT-1 is increased in pregnancies complicated with diabetes, which results in a large infant (Jansson et al., 1999) partly as a result of increased insulin, and insulin-like growth factor 1 expression (Mueckler, 1995). The amount of feeding in late gestation appears to be critical in the maintenance of both placental mass and the abundance of GLUT-1 in ewes that were nutrient restricted during early gestation, as these effects were not observed when the ewes were well fed in late gestation. Increasing food intake in late gestation resulted in an increase in fetal weight by $1-2 \mathrm{~kg}$ and the effects of previous nutrient restriction on fetal length were no longer apparent. These findings indicate that, providing maternal nutrition is adequate to meet both the maternal and fetal metabolic requirements during late gestation, placental GLUT-1 abundance does not limit fetal growth.

The present study focused on GLUT-1, but it is recognized that GLUT-3 is also developmentally regulated in the sheep placenta (Ehrhardt and Bell, 1997), although there is a lack of agreement between GLUT-3 expression and transfer of glucose to the fetus in vivo (Molina et al., 1991). Quantification of GLUT-3 mRNA expression provides little functional information about protein expression, especially in the placenta where tissue of both maternal and fetal origin is present. In addition, the relationship between GLUT-3 mRNA and protein expression appears to be inconsistent, implying that posttranscriptional regulation occurs (Lee et al., 2000). As specific antibodies to ovine GLUT-3 are not currently available (R. Ehrhardt, personal communication), it was not possible to measure its abundance directly. In view of the lack of a consistent relationship between GLUT-1 and fetal size, it is proposed that, as long as the ewe remains normoglycaemic, maternal nutrition is only a limited constraint on fetal size. Providing the metabolic demands for fetal growth are maintained, even when maternal food intake is reduced by $50 \%$, no detrimental effects on fetal size should occur, although fetal sensitivity of the hypothalamic-pituitary-adrenal axis to hypoglycaemia may be reset (Edwards et al., 2001).

The present study confirms that the decrease in placental mass between mid- and late gestation is a result of the loss of large placentomes rather than a consequence of a change in placentome type, as irrespective of maternal nutrition between mid- and late gestation and placental mass at term, placentae of previously nutrient restricted ewes possess more everted placentomes. Placentome eversion has been suggested to occur in response to fetal hypoxia (Penninga and Longo, 1998), but in the studies by Penninga and Longo (1998), no details of maternal feed intake during early to mid gestation were provided. Placentome eversion could be an indicator of changes in the steroid hormone environment within the placenta (Alexander and Williams, 1968). The extent to which an increased abundance of everted 

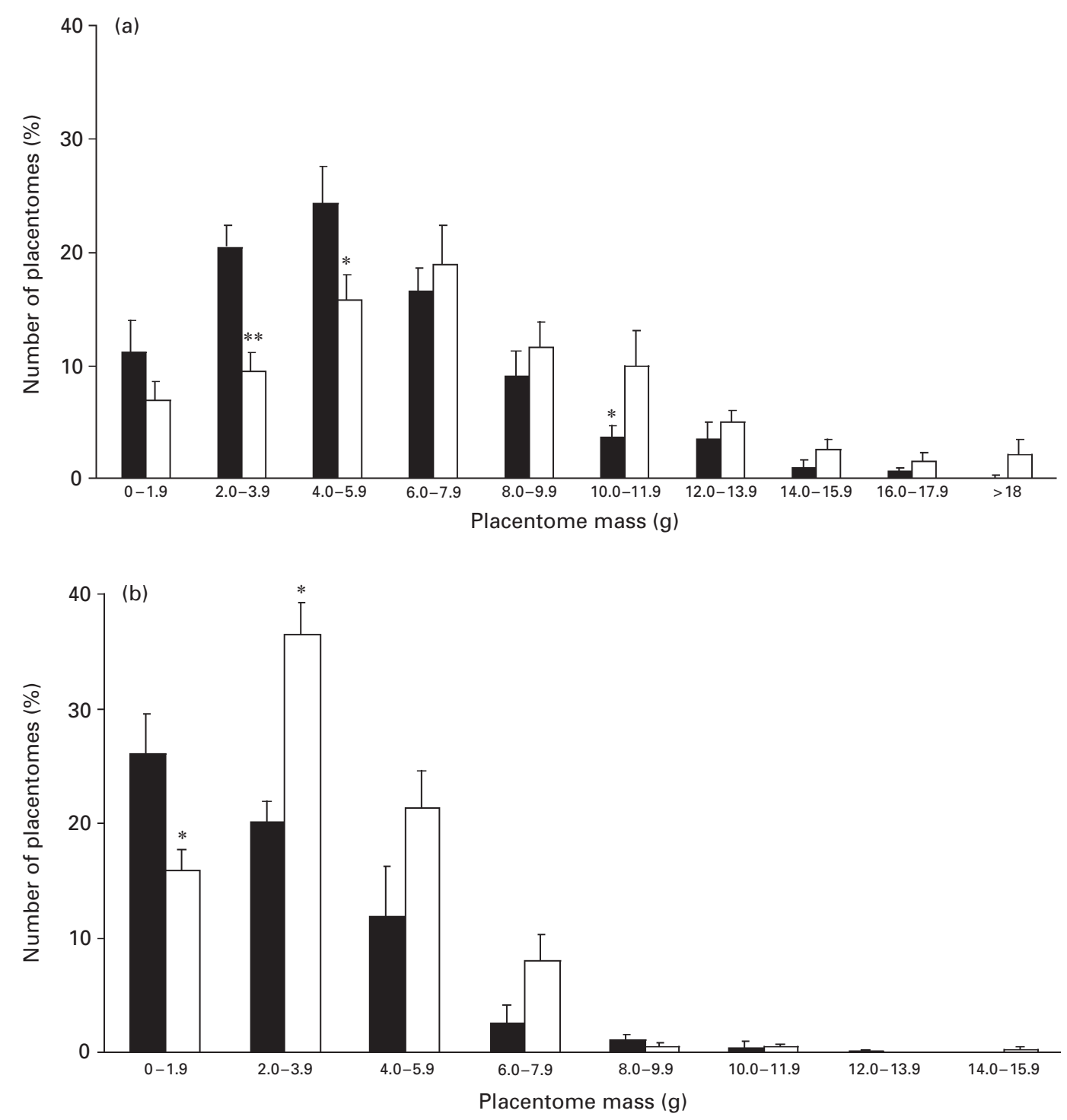

Fig. 5. Distribution of individual placentome masses sampled from well fed $(\square)$ and nutrient restricted ( ewes at (a) day 80 of gestation and (b) near to term that had been either well fed throughout pregnancy ( $\square$ ) or nutrient restricted up to day 80 of gestation and then well fed $(\boldsymbol{\square})$. Values are means \pm SEM and $n=5-7$ per group. Significant differences between groups: ${ }^{*} P<0.05 ; * * P 0.01$.

placentomes alters fetal development, without any effect on birth weight or organ mass, is worthy of further study.

Maternal nutrient restriction between early and midgestation results in a number of fetal endocrine adaptations that persist despite an increase in nutrition. These adaptations include an increase in mRNA for glucocorticoid and type I angiotensin II receptors in the adrenal gland, kidney, liver and lung (Whorwood et al., 2001), as well as increased IGF-II mRNA in skeletal muscle (Brameld et al., 2000). Furthermore, the normal relationship between plasma IGF-I and fetal weight and size are no longer observed near to term in these fetuses (Heasman et al., 2000). Collectively, these programmed tissue-dependent changes in the expression of the specific fetal genes are likely to underlie the molecular adaptations by which maternal undernutrition during early pregnancy increases risk of obesity and cardiovascular disease in offspring, as observed after the Dutch famine (Roseboom et al., 2000a,b).

In conclusion, although maternal nutrient restriction over the period of rapid placental growth restricts placental growth, it has no detrimental effects on the abundance of GLUT-1. When nutrient intake is increased after day 80 of gestation, both placental mass and GLUT-1 abundance can be increased, although this adaptation does not occur if maternal food intake is above the calculated metabolizable energy requirements. 
J. Dandrea and L. Heasman were both supported by Ministry of Agriculture, Fisheries and Food Studentships and G. Gopalakrishnan by a British Heart Foundation Studentship.

\section{References}

Agricultural and Food Research Council (1992) Technical committee on responses to nutrients. In Technical Committee on Responses to Nutrients pp 812-815 Report No. 9. Ed. CAB International, Wallingford, UK

Agricultural Research Council (1980) Requirements for energy. In The Nutritional Requirements of Ruminant Livestock pp 115-119 Ed. Commonwealth Agricultural Bureau, Slough, UK

Alexander G (1964) Studies on the placenta of the sheep (ovis aries I.) Journal of Reproduction and Fertility 7 289-305

Alexander G and Williams D (1968) Hormonal control of amniotic and allantoic fluid volume in ovariectomized sheep Journal of Endocrinology 41 477-485

Barker DJP (1998) Mothers, Babies and Disease in Later Life 2nd Edn. Churchill Livingstone, Edinburgh

Barker DJP, Bull AR, Osmond C and Simmonds SJ (1990) Fetal and placental size and risk of hypertension in adult life British Medical Journal 301 259-262

Barker DJP, Godfrey KM, Osmond C and Bull A (1992) The relation of fetal length, ponderal index and head circumferences to blood pressure and the risk of hypertension in adult life Paediatric and Perinatal Epidemiology 6 35-44

Barros LF, Yudilevich DL, Jarvis SM, Beaumiont N and Baldwin SA (1995) Quantitation and immunolocalisation of glucose transporters in the human placenta Placenta 16 623-633

Bispham JR, Heasman L, Clarke L, Ingleton PM, Stephenson T and Symonds ME (1999) Effect of maternal dexamethasone treatment and ambient temperature on prolactin receptor abundance in brown adipose and hepatic tissue in the fetus and newborn lamb Journal of Neuroendocrinology 11 849-856

Brameld JM, Mostyn A, Dandrea J, Stephenson TJ, Dawson J, Buttery PJ and Symonds ME (2000) Maternal nutrition alters the expression of insulin-like growth factors in fetal sheep liver and skeletal muscle Journal of Endocrinology 167 429-437

Clarke L, Heasman L, Juniper DT and Symonds ME (1998) Maternal nutrition in early- to mid-gestation and placental size in sheep British Journal of Nutrition 79 359-364

Currie MJ, Bassett NS and Gluckman PD (1996) Ovine glucose transporter1 and -3 : cDNA partial sequences and developmental gene expression in the placenta Placenta 18 393-402

Devaskar SU, Devaskar UP, Schroeder RE, de Mello DE, Fiedorek FT and Mueckler M (1994) Expression of genes involved in placental glucose uptake and transport in the nonobese diabetic mouse pregnancy American Journal of Obstetrics and Gynecology 171 1316-1323

Edwards LJ, Symonds ME, Warnes K, Owens JA, Butler TG, Jurisevic A and McMillen IC (2001) Responses of the fetal pituitary-adrenal axis to acute and chronic hypoglycaemia during late gestation in the sheep Endocrinology 142 1778-1785

Ehrhardt RA and Bell AW (1995) Growth and metabolism of the ovine placenta during mid-gestation Placenta $16727-741$

Ehrhardt RA and Bell AW (1997) Developmental increases in glucose transporter concentration in the sheep placenta American Journal of Physiology 273 R1132-R1141

Heasman L, Clarke L, Firth K, Stephenson T and Symonds ME (1998) Influence of restricted maternal nutrition in early- to mid-gestation on placental and fetal development at term Pediatric Research 44 546-551

Heasman L, Clarke L, Stephenson T and Symonds ME (1999) The influence of maternal nutrient restriction in early- to mid-pregnancy on placental and fetal development in sheep Proceedings of the Nutrition Society $\mathbf{5 8}$ 283-288
Heasman L, Brameld JM, Mostyn A, Budge H, Dawson J, Buttery PJ, Stephenson T and Symonds ME (2000) Maternal nutrient restriction during early- to mid-gestation alters the relationship between IGF-I and body size at term in fetal sheep Reproduction, Fertility and Development $12345-350$

Jansson T, Wennergren M and Powell TL (1999) Placental glucose transport and GLUT-1 expression in insulin-dependent diabetes American Journal of Obstetrics and Gynecology 180 163-168

Lee DH, Chung MY, Lee JU, Kang DG and Paek YW (2000) Changes of glucose transporters in the cerebral adaptation to hypoglycemia Diabetes Research and Clinical Practice 47 15-23

Lowry OH, Rosenbrough NJ, Farr AL and Randall RJ (1951) Protein measurement with the Folin phenol reagent Journal of Biological Chemistry 193 265-275

Lumey LH (1998) Compensatory placental growth after restricted nutrition in early pregnancy Placenta 19 105-112

McCrabb GJ, Egan AR and Hosking BJ (1991) Maternal undernutrition during mid-pregnancy in sheep. Placental size and its relationship to calcium transfer during late pregnancy British Journal of Nutrition 65 157-168

McCrabb GJ, Egan AR and Hosking BJ (1992) Maternal undernutrition during mid-pregnancy in sheep: variable effects on placental growth Journal of Agricultural Science, Cambridge 118 127-132

Meschia G, Battaglia FC, Hay WW and Sparks JW (1980) Utilization of substrates by the ovine placenta Federation Proceedings 39 245-249

Molina RD, Meschia G, Battaglia FC and Hay WW (1991) Gestational maturation of placental transfer of glucose American Journal of Physiology 261 R697-R704

Mueckler M (1995) Facilitative glucose transporters European Journal of Endocrinology 132 206-212

Penninga L and Longo LD (1998) Ovine placental morphology: effect of high altitude, long-term hypoxia Placenta 19 187-193

Roseboom TJ, van der Meulen JHP, Ravelli ACJ, von Montfrans S-T, GA, Osmond C, Barker DJP and Blecker OP (1999) Blood pressure in adults after perinatal exposure to famine Journal of Hypertension 17 325-330

Roseboom TJ, van der Meulen JHP, Osmond C, Barker DJP, Ravelli ACJ, von Montfrans S-T, GA, Michels RPJ and Blecker OP (2000a) Coronary heart disease in adults after perinatal exposure to famine Heart 84 595-598

Roseboom TJ, van der Meulen JHP, Ravelli ACJ, Osmond C, Barker DJP and Blecker OP (2000b) Plasma fibrinogen and factor VII concentrations in adults after perinatal exposure to famine British Journal of Haematology 111 112-117

Russel AJF, Doney JM and Gunn RG (1969) Subjective assessment of body fat in live sheep Journal of Agricultural Science, Cambridge 72 451-454

Stegmann JHJ (1974) Placental development in sheep Bijdragen tot de Dierkunde 44 4-72

Symonds ME, Bryant MJ and Lomax MA (1986) The effect of shearing on the energy metabolism of the pregnant ewe British Journal of Nutrition $\mathbf{5 6}$ 635-643

Vatnick I, Schoknecht PA, Darrigrand R and Bell AW (1991) Growth and metabolism of the placenta after unilateral fetectomy in twin pregnant ewes Journal of Developmental Physiology 15 351-356

Whorwood CB, Firth KM, Budge H and Symonds ME (2001) Maternal undernutrition during early- to mid-gestation programmes tissuespecific alterations in the expression of the glucocorticoid receptor, $11 \mathrm{~b}$ hydroxysteroid dehydrogenase isoforms and type 1 angiotensin II receptor in neonatal sheep Endocrinology 142 2854-2864

Zhou J and Bondy CA (1993) Placental glucose transporter gene expression and metabolism in the rat Journal of Clinical Investigation 91 845-852

Received 13 January 2001.

First decision 9 March 2001.

Accepted 19 July 2001. 